\title{
Androgen Deprivation Therapy and Cardiovascular Risk
}

\author{
Kherad $B^{* 1,2}$, Spillmann $F^{1}$, Noutsias $M^{3}$, Tschöpe $C^{1,4,5}$ and Krackhardt $F^{1}$ \\ ${ }^{1 *}$ Department of Cardiology, Universitätsmedizin Berlin, Campus Virchow Klinikum (CVK), Berlin \\ ${ }^{2}$ Privatpraxis Dr. Kherad, Große Hamburger Strasse 5-11, 10115 Berlin, Germany \\ ${ }^{3}$ Mid-German Heart Center, Department of Internal Medicine III, Division of Cardiology, Angiology and Intensive Medical Care, University Hospital \\ Halle, Germany \\ ${ }^{4}$ Berliner Zentrum für Regenerative Therapien (BCRT), Campus Virchow Klinikum (CVK) \\ ${ }^{5}$ Deutsches Zentrum für Herz Kreislaufforschung (DZHK) - Standort Berlin/Charité
}

${ }^{*}$ Correspondence to: Dr. med. Behrouz Kherad, Charité - Universitätsmedizin Berlin, Campus Virchow Clinic Department of Cardiology, Augustenburgerplatz 1, 13353 Berlin, Germany, Tel: +49 (0)30 / 450-55 3712 Fax: +49 (0)30 / 450-755 37 12; Email: Behrouz.kherad@charite.de

Received: October 20, 2017; Accepted: October 30, 2017; Published: November 08, 2017;

\begin{abstract}
Background: Several studies have suggested that patients with prostate cancer who undergo androgen deprivation therapy (ADT) with a GnRH agonist have an increased risk of experiencing a cardiovascular event. GnRH antagonists have a different mode of action to GnRH agonists and may be a safer alternative to GnRH agonists in ADT.

Objectives: This review article aims to discuss potential mechanisms underlying the development of cardiovascular events associated with ADT using GnRH agonists and to explain the differences in mode of action between GnRH agonists and GnRH antagonists. Additionally, relevant studies are presented and practical recommendations for clinical practice are provided.
\end{abstract}

Methods: A literature research was performed. Full publications and abstracts published in the last 10 years until September $1^{\text {st }} 2015$ were considered to be eligible.

Results: GnRH antagonists were associated with a decreased risk of cardiovascular events compared to GnRH agonists in prostate cancer patients undergoing ADT, and in particular those patients with cardiovascular risk factors or a history of cardiovascular disease. This decrease may be due to the differential mode of action of GnRH antagonists, compared with GnRH agonists.

Conclusions: Prostate cancer patients undergoing ADT with either cardiovascular disease or an increased risk of experiencing a cardiovascular event should be evaluated for their cardiovascular risk and preferentially treated with a GnRH antagonist.

Keywords: Androgen deprivation therapy, cardiovascular risk, GnRH agonist, GnRH antagonist

\section{Introduction}

Androgen deprivation therapy (ADT) with GnRH agonists, $\mathrm{GnRH}$ antagonists, and orchiectomy play an important role in the treatment of patients with prostate cancer. ADT therapy has been shown to induce adverse effects including obesity, insulin resistance, hyperglycaemia, dyslipidaemia, and hypertension. All of these adverse effects are associated with the consecutive incidence of diabetes and cardiovascular events under ADT [1]. Therefore, it is important to evaluate potential correlations of cardiovascular adverse-effects and $\mathrm{ADT}$, and furthermore to develop practical recommendations for urologist and cardiologist, as the majority of patients with prostate cancer die of non-cancer related diseases [2].

This review article presents an overview of the various functions of androgens and the resulting pathogenesis of cardiac events/diseases that can be caused by ADT. Moreover, the potential relationships between GnRH agonists / antagonists and cardiac events under ADT are explained, including the type of testosterone deprivation of both substance classes, and the relevant clinical studies are summarized.
Moreover, practical recommendations for clinical practice are provided.

\section{Hormonal effects of androgens on the cardiovascular system}

Androgens play a decisive role in the energy supply and in various metabolic pathways of cells besides their fundamental role in reproductive and sexual function. Androgens have a systemic indirect effect on the cardiovascular system and a direct effect on the cardiovascular system.

Androgens promote growth and preservation of muscle mass and promote fat metabolism, thereby regulating the body composition [3]. Expression of androgen receptors in fat tissue suggests that androgens are involved in the accumulation and distribution of fat tissue. Androgens promote lipolysis in adipose tissue and inhibit the absorption of triglycerides, thus increasing levels of circulating triglycerides and cholesterol. Moreover, androgens ensure a faster conversion of triglycerides into subcutaneous abdominal fat tissue, and less into gluteal-femoral fat [4]. 
Testosterone, the most prominent member of the androgens, has been shown to have direct positive and negative effects on the cardiovascular system. Testosterone has been shown to have an antiarrhythmic effect on the heart $[5,6]$, protect the cardiomyocytes against ischemic insults, thereby reducing the myocardial infarction size $[7,8]$, and its atheroprotective effects have been proven, as well [9-11].

On the other hand, testosterone is reported to have negative effects on the endothelium [12], on vasorelaxation [13], and it promotes apoptosis [14].

These discrepancies of biological effects may explain the differential clinical results of the type and dosage of testosterone deprivation on the cardiovascular system. For instance, patients who underwent orchiectomy suffer less often from coronary heart disease, myocardial infarction, sudden cardiac death and stroke as compared to patients who are treated with GnRH agonists [15].

\section{Indirect and direct effects of GnRH agonists on the cardio- vascular system}

The U.S. Food and Drug Administration (FDA) issued a warning for GnRH agonists on the basis of a number of published data which associated GnRH agonist treatment with an increased risk of cardiovascular events [15]. The effects GnRH agonist treatment on the cardiovascular system can be explained with its indirect and direct effects on the cardiovascular system.

\section{Indirect mechanisms}

Therapy with GnRH agonists aims at reducing the androgen level resulting in an induced state of hypogonadism. The effects of GnRH agonist treatment include effects on sexual function including reduced libido, impotence and systemic effects including anaemia, and osteoporosis [16].

The changes in the body composition, which are also observed in patients treated with GnRH agonists, characterised by a loss of muscle mass and strength and increase in fat tissue and weight gain can be attributed to the fact that androgen-mediated effects on adipogenesis are inhibited [17].

The observed increase in the fat mass has been shown to be associated with increased insulin levels $[18,19]$ which in turn might also promote the production of adipokines and inflammatory cytokines [20]. These changes lead to increased plasma insulin concentrations, insulin resistance, increased HDL and LDL levels, and higher triglyceride levels $[3,21]$. These changes promote the incidence of diabetes. Diabetes and the metabolic disorders are independent risk factors for the development of atherosclerosis, which in turn increases the risk for the incidence or progression of cardiovascular diseases.

\section{Direct mechanisms}

Binding of $\mathrm{GnRH}$ to its receptor has been shown to occur at several sites of the body, including the hypothalamus, pituitary gland, gonads, breast, and prostate. The expression of the GnRH receptor outside the hypothalamus-pituitary gland-reproduction-axis, such as the cerebellum, kidney, and heart is currently under investigation [22].
Studies suggest that GnRH agonists have a direct effect on the cardiomyocytes which might affect the cardiac function negatively. GnRH agonists are believed to regulate the heart contractility and the concentration of intracellular calcium ions by activating the protein kinase A (PKA) through the GnRH receptor. Cardiomyocytes contain substrates of PKA such as phospholamban, L-type calcium channel, and components of the contractile apparatus. Thus, the PKA could play a decisive role in the GnRH associated cardiac reaction [23].

The GnRH receptor is also present on lymphocytes that even produce GnRH endogenously to regulate the immune function [24]. The transendothelial migration of infiltrates is mediated by interactions of cell adhesion molecules, which are induced by cytokines [25]. Binding of GnRH or GnRH agonist to the GnRH receptor on the lymphocytes leads to an increased expression of the IL2 $\gamma$ receptor [24]. This results in an increased proliferation and inflammation as well as the release of cytokines like interferon $\gamma$. Inflammatory processes impair the normal function of the endothelium so that the development of atherosclerotic plaques, instabilities, and plaque ruptures are promoted $[26,27]$. These are supposed to be the main cause for acute myocardial infarctions and strokes.

\section{Differences in the mode of action between GnRH agonists and antagonists}

Since the FDA assumed a class effect regarding cardiovascular events, they also issued 3 years after the initial warning for $\mathrm{GnRH}$ agonists, a black-label-warning for $\mathrm{GnRH}$ antagonists [28]. However, the FDA did not take into account the fact that GnRH agonists and antagonists were not considered separately in studies, and they did not consider that their differential mode of action:

$\mathrm{GnRH}$ agonists act like the natural ligand, $\mathrm{GnRH}$, of the $\mathrm{GnRH}$ receptor. By binding to the receptor, they induce activation so that the luteinising hormone (LH) and follicle-stimulating hormone (FSH), which are initially released in increased amounts. This results in a temporary testosterone surge (flare up). However, by continuous administration of a GnRH agonist, the GnRH receptor is permanently stimulated and thus down-regulated. This down-regulation in turn causes a permanent reduction of LH and FSH hormones as well as of testosterone levels to the orchiectomy level.

GnRH antagonists do not act like a ligand that stimulates the $\mathrm{GnRH}$ receptor, but block it competitively, and thus inhibit the release of LH and FSH. There is no flare-up, as due to the inhibition of the GnRH receptor all subsequent LH- and FSH-mediating signal pathways downstream of the $\mathrm{GnRH}$ receptor are also blocked.

Several non-randomised studies have shown that ADT with GnRH agonists is associated with an increased cardiovascular risk [15, 29-37]. In contrast, several randomised studies report no correlation between the administration of GnRH agonists and an increased cardiovascular risk [38-41] (see table 1). However, the contradictory results can be attributed to several potential sources of error in the respective study design [11].

In contrast to these results, a large meta-analysis of 16 prospective phase II/III studies and one phase III study, analysing 1,704 patients treated with the GnRH antagonist degarelix showed no correlation between the treatment and cardiovascular events [42]. 
Table 1: Non-randomised trial for the evaluation of the incidence of cardiovascular events under GnRH agonists in men with prostate cancer.

\begin{tabular}{|c|c|c|c|c|c|}
\hline Ref. & n & Reference group & ADT & Result & HR $(95 \% \text { CI })^{1}$ \\
\hline [17] & 73,196 & no ADT & $\begin{array}{l}\text { GnRH agonist and/or } \\
\text { antiandrogen }\end{array}$ & $\begin{array}{l}\text { Coronary heart disease, myocardial infarction, sudden } \\
\text { cardiac death }\end{array}$ & $\begin{array}{l}1.16(1.10-1.21) \\
1.11(1.01-1.21) \\
1.16(1.05-1.27)\end{array}$ \\
\hline [36] & 4,892 & no ADT & $\begin{array}{l}\text { GnRH agonist and/or } \\
\text { antiandrogen }\end{array}$ & $\begin{array}{l}\text { Cardiovascular mortality with radical prostatectomy, } \\
\text { cardiovascular mortality with EBRT, brachytherapy or } \\
\text { chemotherapy, }\end{array}$ & $\begin{array}{l}2.6(1.4-1.7) \\
1.2(0.8-1.9)\end{array}$ \\
\hline [37] & 22,816 & no ADT & Medical ADT & Cardiovascular morbidity & $1.20(1.15-1.26)$ \\
\hline [40] & 19,097 & no ADT & $\begin{array}{l}\text { GnRH agonist and/or } \\
\text { antiandrogen; orchiectomy }\end{array}$ & $\begin{array}{l}\text { Acute myocardial infarction, sudden cardiac death, } \\
\text { diabetes }\end{array}$ & $\begin{array}{l}0.92(0.84-1.00) \\
0.96(0.83-1.10) \\
1.24(1.15-1.35)\end{array}$ \\
\hline [33] & 37,443 & WW/AS & $\begin{array}{l}\text { GnRH agonist, orchiectomy, } \\
\text { antiandrogen, combined } \\
\text { androgen blockade }\end{array}$ & $\begin{array}{l}\text { Coronary heart disease, myocardial infarction, sudden } \\
\text { cardiac death, stroke }\end{array}$ & $\begin{array}{l}1.17(1.06-1.39) \\
1.21(1.01-1.44) \\
1.28(1.05-1.57) \\
1.18(1.02-1.36)\end{array}$ \\
\hline [34] & 76,601 & RP, WW/AS & $\begin{array}{l}\text { GnRH agonist, antiandrogen, } \\
\text { GnRH + antiandrogen, } \\
\text { orchiectomy, medical or } \\
\text { surgical ADT }\end{array}$ & $\begin{array}{l}\text { Ischemic heart disease, myocardial infarction, heart } \\
\text { failure, stroke }\end{array}$ & $\begin{array}{l}1.34(1.25-1.43) \\
1.47(1.35-1.60) \\
1.67(1.54-1.80) \\
1.27(1.17-1.38)\end{array}$ \\
\hline [38] & 182,757 & no ADT & GnRH agonist, orchiectomy & Peripheral arterial disease, venous thromboembolism & $\begin{array}{l}1.15(1.11-1.19) \\
1.10(1.04-1.16)\end{array}$ \\
\hline [35] & 31,571 & no ADT & Antiandrogen, orchiectomy & Myocardial infarction, stroke & $\begin{array}{l}1.31(1.16-1.49) \\
1.19(1.06-1.35)\end{array}$ \\
\hline [39] & 140,474 & no ADT & GnRH agonist, orchiectomy & $\begin{array}{l}\text { Acute myocardial infarction, coronary artery disease, } \\
\text { sudden cardiac death }\end{array}$ & $\begin{array}{l}1.09(1.04-1.15) \\
1.11(1.07-1.15) \\
1.18(1.12-1.24)\end{array}$ \\
\hline [41] & 50,384 & no ADT & GnRH agonist, orchiectomy & Coronary heart disease & $\begin{array}{l}1.13(1.09-1.17)-1.17(1.13-1.21) \\
\text { dose-dependent }\end{array}$ \\
\hline
\end{tabular}

${ }^{1}$ If several types of ADT are evaluated separately, HRs refer to GnRH agonists vs. control.

In order to clearly attribute the incidence of cardiovascular events under medical ADT to one substance class, a direct comparison between GnRH agonists and GnRH antagonists in clinical studies is required.

Such a comparison was performed in the recently published meta-analysis by Albertsen et al. between the GnRH antagonist degarelix and the GnRH agonists goserelin and leuprolide [33, 43]. Data of 2,328 patients from six prospective RCTs were pooled. 1,491 patients received degarelix and of the remaining 837 patients, 458 patients were treated with goserelin and 379 patients with leuprolide, respectively. Patients treated with the GnRH antagonist degarelix had a significantly lower risk of experiencing a cardiovascular event as compared to patients under GnRH agonist therapy (HR: 0.597; 95\% CI: $0.380-0.938 ; p=0.0253$ ) [44]. A subsequent analysis using a Cox model confirmed these results. Treatment with the GnRH antagonist degarelix resulted in a $40 \%$ lower risk of experiencing a cardiovascular event or death compared to treatment with GnRH agonists (HR: 0.60; 95\% CI: 0.41-0.87; $\mathrm{p}=0.008$ ) [43].

\section{Treatment of patients with known cardiovascular disease}

Several studies suggest that patients with a history of cardiovascular disease have a higher risk of experiencing a cardiovascular event under ADT.

In the above mentioned meta-analysis of 16 prospective phase II/ III studies and one phase III study, analysing 1,704 patients treated with the GnRH antagonist degarelix, the patients were stratified according to their cardiovascular history. Patients in group $1(n=337)$ had no cardiovascular risk factors, patients in group $2(n=803)$ had one cardiovascular risk factor, but no cardiovascular disease, and patients in group $3(\mathrm{n}=112)$ had a known cardiovascular disease. Cardiovascular events were most frequent in patients with the most severe cardiovascular history in group 3 (20\%), decreasing in the other 
groups (group 2: $8 \%$ and group 1: 7\%). While the presence of a single risk factors only resulted in a 1.3 fold increased risk of experiencing a cardiovascular event $(\mathrm{p}=0.28)$, an existing cardiovascular event resulted in a 3.1 fold increased risk $(\mathrm{p}<0.0001)$ [42].

A direct comparison between $\mathrm{GnRH}$ agonists and the GnRH antagonist degarelix revealed that degarelix was associated with a significantly lower risk of experiencing a cardiovascular event in patients with a history of cardiovascular disease. Thus, there were significantly fewer cardiovascular (HR: 0.476 ; 95\% CI: 0.260-0.871; $\mathrm{p}=0.0160$ ) or severe cardiovascular events (HR: $0.367 ; 95 \% \mathrm{CI}$ : 0.174-0.775; $\mathrm{p}=0.0086$ ) under degarelix compared to LHRH agonists (Figure 1) [44]. A landmark analysis of the first treatment year with GnRH antagonists in patients with known cardiovascular disease revealed a 56\% lower risk (HR: 0.44; 95\% CI: 0.26-0.74; $\mathrm{p}=0.002$ ) [43] for experiencing cardiovascular events (arterial embolic and thrombotic events, haemorrhagic or ischemic cerebrovascular events, myocardial infarction, or other ischemic heart diseases) or death as compared to GnRH agonists (Figure 2). In patients without cardiovascular history, no different cardiovascular risk was observed depending on the respective ADT.

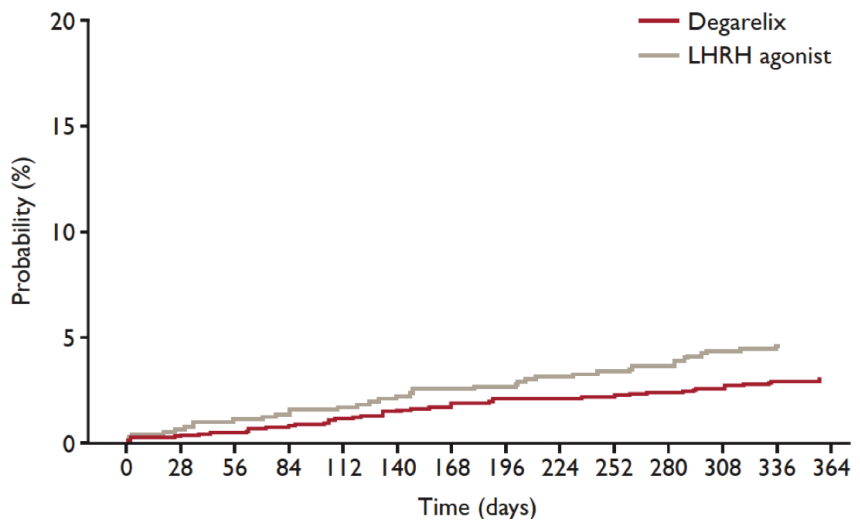

Figure 1: Cardiovascular risk in all patients

A direct comparison between GnRH agonists and the GnRH antagonist degarelix revealed that degarelix was associated with a significantly lower risk of experiencing a cardiovascular event in patients with a history of cardiovascular disease. Thus, there were significantly fewer cardiovascular (HR: $0.476 ; 95 \%$ CI: $0.260-0.871 ; \mathrm{p}=0.0160$ ) or severe cardiovascular events (HR: $0.367 ; 95 \%$ CI: 0.174-0.775; $\mathrm{p}=0.0086$ ) under degarelix compared to LHRH agonists (modified from [44]).

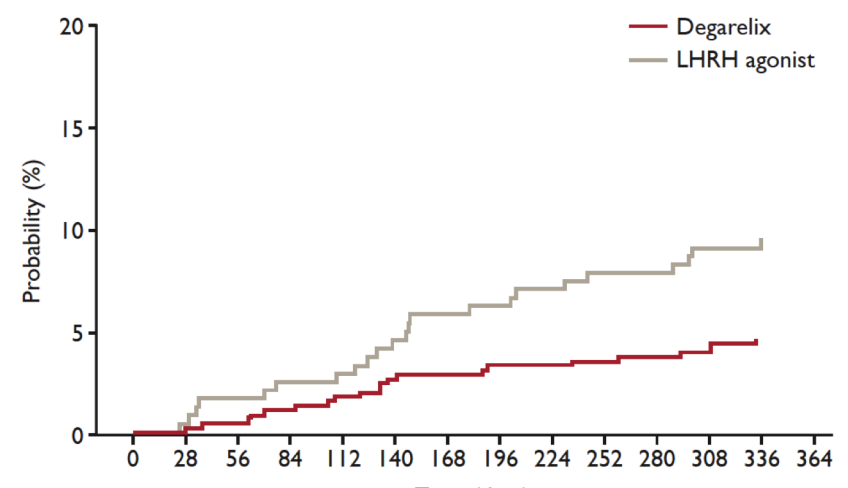

Figure 2: Landmark analysis of first treatment year.

A landmark analysis of the first treatment year with GnRH antagonists in patients with known cardiovascular disease revealed a $56 \%$ lower risk (HR: 0.44 ; $95 \%$ CI: $0.26-0.74$; $\mathrm{p}=0.002$ ) for experiencing cardiovascular events or death as compared to $\mathrm{GnRH}$ agonists (modified from [43]).
One possible explanation for the lower risk of $\mathrm{GnRH}$ antagonists as compared to GnRH agonists in patients with history of cardiovascular disease might be the low rate of vascular occlusions which is probably associated with FSH. FSH receptors play a role in the lipid metabolism and fat accumulation so that their inhibition might reduce the risk of experiencing a repeated cardiovascular event [45]. GnRH antagonists suppress both LH and FSH hormones [28, 46, 47]. In contrast, GnRH agonists primarily inhibit the release of $\mathrm{LH}$ and therefore do not act sufficiently on the signal pathways downstream of FSH [43]. Another possible cause could be the destabilisation of vascular lesions under ADT. Destabilisation might be achieved by activating GnRH receptors on the T-cells atherosclerotic plaques with a GnRH agonist. This mechanism does not apply for GnRH antagonists, as these do not induce activation of the $\mathrm{GnRH}$ receptor.

\section{Consequences for therapy management}

With regard to therapy management it seems obvious that patients with a history of cardiovascular disease or the risk of developing a cardiovascular disease should be preferentially treated with a $\mathrm{GnRH}$ antagonist over a GnRH agonist. Alternatively, a dose reduction of the GnRH agonist could be useful [37]. However, this should be carefully weighed, as a dose reduction can always impair treatment efficacy.

According to a recently published meta-analysis, the benefits of a GnRH antagonist can not only have a positive effect on the sideeffect profile, but also improve the overall survival as compared to therapy with a GnRH agonist. Klotz et al. report that patients under $\mathrm{GnRH}$ antagonist therapy had a significantly longer progression-free survival. Moreover, these patients also have a more favourable sideeffect profile regarding urinary and musculoskeletal tract as compared to patients under a GnRH agonist [48]. Although these findings provided first indications for the benefits of treatment with a $\mathrm{GnRH}$ antagonist, they must be further validated.

\section{Outlook and recommendations}

Cardiovascular diseases are the major cause of death in the male population of advanced age. In order to avoid any additional lifethreatening risks for this patient population, different therapeutic approaches to ADT should be evaluated for their potential cardiovascular side-effects. Current evidence shows that treatment using GnRH agonists provides better cardiovascular tolerability and should thus be preferred. However, further clinical studies are required to directly compare the incidence of cardiovascular events under GnRH agonists as compared to $\mathrm{GnRH}$ antagonists. One trial currently still recruiting patients who is comparing cardiovascular safety of degarelix versus leuprolide in patients with advanced prostate cancer and cardiovascular disease is the PRONOUNCE Trial (NCT02663908).

Thus, patients with prostate cancer are mainly elder patients with additional traditional cardiovascular risk factors. If ADT becomes necessary, the cardiovascular risk is further adversely affected. Therefore, the patient's cardiovascular risk should be taken into consideration before the appropriate treatment option is selected and treatment initiated.

Patients with a high cardiovascular risk or who have already experienced a cardiovascular event might particularly benefit from treatment with a GnRH antagonist. Nevertheless, these patients should be 
monitored closely in coordination with the attending cardiologists. This will enable optimal adjustment of the treatable risk factors, like the lipid profile as well as blood pressure. The same applies for patients suffering from diabetes or a prediabetic metabolic status. These parameters should be verified and - if necessary - adjusted prior to therapy. The next step should be cessation of nicotine abuse. The highest risk of experiencing a cardiovascular event is at the beginning of the therapy. It is very important that the patient is screened for potential cardiovascular risk factors or known risk factors optimally adjusted, respectively.

We suggest that all patients scheduled to undergo ADT therapy should have a cardiovascular assessment.

Cardiovascular assessment should include a thorough physical examination, assessment of any cardiac related symptoms (angina, dyspnea, syncope and palpitations), history taking of any known cardiovascular disease, and determination of the presence of cardiovascular risk factors such as hypertension, diabetes, smoking habit, adiposities, hyperlipidemia, myocardial infarction, heart failure and stroke. In patients with known diabetes, we recommend to determine the $\mathrm{HbAlc}$ before the start of the ADT treatment. We furthermore recommend monitoring the $\mathrm{HbAlc}$ levels during the therapy. In patients with known hyperlipidemia we recommend to further monitor the levels of cholesterol, triglyceride, LDL and HDL.

Patients with one or more cardiovascular risk factors should be assessed furthermore. We recommend a resting-ECG for all patients with more than 1 risk factors or known coronary artery disease, echocardiography for patients with known/suspected heart failure and/or known/suspected valve disease, a treadmill-testing for patients with $>3$ cardiovascular risk factors and/or unstable angina and invasive angiogram for patients with suspected coronary artery disease (see Figure 3).

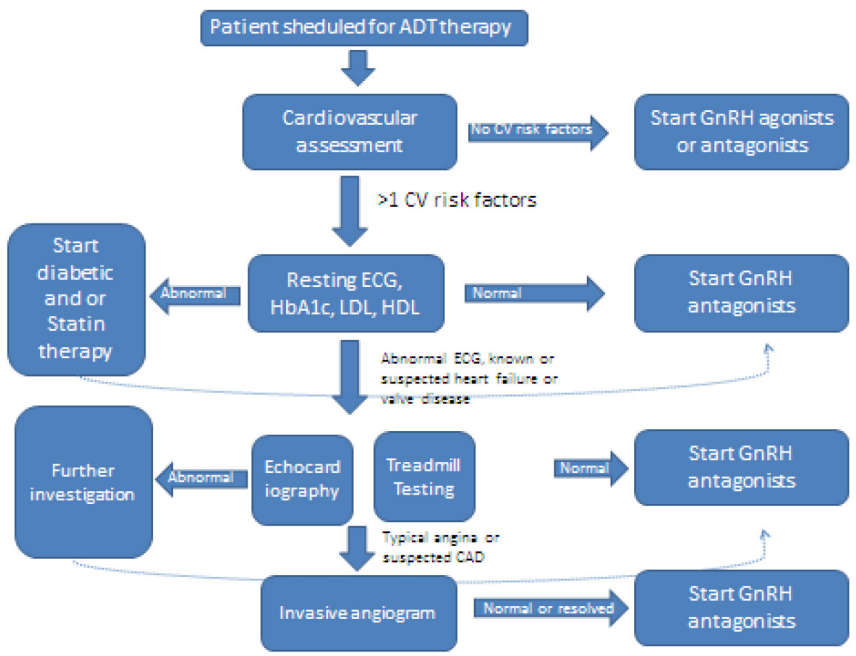

Figure 3: Clinical recommendations.

Patients with known cardiovascular disease should be on optimal doses of beta blocker, statin, ACE-inhibitor/ ARB and diuretic therapy.

\section{References}

1. Collier A, Ghosh S, McGlynn B, Hollins G: Prostate cancer, androgen deprivation therapy, obesity, the metabolic syndrome, type 2 diabetes, and cardiovascular disease: a review. American journal of clinical oncology 35: 504-509.
2. Feuer EJ, Merrill RM, Hankey BF (1999) Cancer surveillance series: interpreting trends in prostate cancer--part II: Cause of death misclassification and the recent rise and fall in prostate cancer mortality. Journal of the National Cancer Institute 91: 1025-1032.

3. Smith MR, Finkelstein JS, McGovern FJ, Zietman AL, Fallon MA, et al. (2002) Changes in body composition during androgen deprivation therapy for prostate cancer. J Clin Endocrinol Metab 87: 599-603. [crossref]

4. Collins L, Mohammed N, Ahmad T, Basaria S (2012) Androgen deprivation therapy for prostate cancer: implications for cardiometabolic clinical care. Journal of endocrinological investigation 35: 332-339.

5. Edelman S, Butler J, Hershatter BW, Khan MK (2014) The Effects of Androgen Deprivation Therapy on Cardiac Function and Heart Failure: Implications for Management of Prostate Cancer. Clinical genitourinary cancer 12: 399-407.

6. Brouillette J, Rivard K, Lizotte E, Fiset C (2005) Sex and strain differences in adult mouse cardiac repolarization: importance of androgens. Cardiovascular research 65: $148-157$.

7. Tsang S, Wu S, Liu J, Wong TM (2008) Testosterone protects rat hearts against ischaemic insults by enhancing the effects of alpha(1)-adrenoceptor stimulation. $\mathrm{Br}$ J Pharmacol 153: 693-709. [crossref]

8. Herring MJ, Oskui PM, Hale SL, Kloner RA (2013) Testosterone and the cardiovascular system: a comprehensive review of the basic science literature. Journal of the American Heart Association 2: e000271.

9. Bourghardt J, Wilhelmson AS, Alexanderson C, De Gendt K, Verhoeven G, et al. (2010) Androgen receptor-dependent and independent atheroprotection by testosterone in male mice. Endocrinology 151: 5428-5437.

10. Kelly DM, Jones TH (2013) Testosterone: a vascular hormone in health and disease. J Endocrinol 217: R47-71. [crossref]

11. Tivesten A, Pinthus JH, Clarke N, Duivenvoorden W, Nilsson J (2015) Cardiovascular risk with androgen deprivation therapy for prostate cancer: potential mechanisms. Urol Oncol 33: 464-475. [crossref]

12. Rettew JA, Huet-Hudson YM, Marriott I (2008) Testosterone reduces macrophage expression in the mouse of toll-like receptor 4, a trigger for inflammation and innate immunity. Biology of reproduction 78: 432-437.

13. Ammar EM, Said SA, Hassan MS (2004) Enhanced vasoconstriction and reduced vasorelaxation induced by testosterone and nandrolone in hypercholesterolemic rabbits. Pharmacological research: the official journal of the Italian Pharmacological Society 50: 253-259.

14. Cavasin MA, Tao ZY, Yu AL, Yang XP (2006) Testosterone enhances early cardiac remodeling after myocardial infarction, causing rupture and degrading cardiac function. American journal of physiology Heart and circulatory physiology 290: H2043-2050.

15. Keating NL, O'Malley AJ, Smith MR (2006) Diabetes and cardiovascular disease during androgen deprivation therapy for prostate cancer. Journal of clinical oncology: official journal of the American Society of Clinical Oncology 24: 44484456.

16. Taylor LG, Canfield SE, Du XL (2009) Review of major adverse effects of androgen-deprivation therapy in men with prostate cancer. Cancer 115: 2388-2399.

17. Bhasin S, Taylor WE, Singh R, Artaza J, Sinha-Hikim I, Jasuja R, et al. (2003) The mechanisms of androgen effects on body composition: mesenchymal pluripotent cell as the target of androgen action. The journals of gerontology Series A, Biological sciences and medical sciences 58: M1103-1110.

18. Traish AM, Saad F, Guay A (2009) The dark side of testosterone deficiency: II. Type 2 diabetes and insulin resistance. $J$ Androl 30: 23-32. [crossref]

19. Smith MR, Lee H, Fallon MA, Nathan DM (2008) Adipocytokines, obesity, and insulin resistance during combined androgen blockade for prostate cancer. Urology 71: 318-322.

20. Shahani S, Braga-Basaria M, Basaria S (2008) Androgen deprivation therapy in prostate cancer and metabolic risk for atherosclerosis. The Journal of clinical endocrinology and metabolism 93: 2042-2049.

21. Dockery F, Bulpitt CJ, Agarwal S, Donaldson M, Rajkumar C (2003) Testosterone suppression in men with prostate cancer leads to an increase in arterial stiffness and hyperinsulinaemia. Clinical science (London, England : 1979) 104: 195-201.

22. Skinner DC, Albertson AJ, Navratil A, Smith A, Mignot M, et al. (2009) Effects of gonadotrophin-releasing hormone outside the hypothalamic-pituitary-reproductive axis. Journal of neuroendocrinology 21: 282-292.

23. Dong F, Skinner DC, Wu TJ, Ren J (2010) The heart: a novel gonadotrophinreleasing hormone target. Journal of neuroendocrinology 23: 456-463.

24. Chen HF, Jeung EB, Stephenson M, Leung PC (1999) Human peripheral blood mononuclear cells express gonadotropin-releasing hormone (GnRH), GnRH receptor, and interleukin-2 receptor gamma-chain messenger ribonucleic acids that are regulated by GnRH in vitro. The Journal of clinical endocrinology and metabolism 84: 743-750

25. Noutsias M, Seeberg B, Schultheiss HP, Kuhl U (1999) Expression of cell adhesion molecules in dilated cardiomyopathy: evidence for endothelial activation in inflammatory cardiomyopathy. Circulation 99: 2124-2131. 
26. Knutsson A, Hsiung S, Celik S, Wigren M, Nilsson J, et al. (2015) Treatment with an LRHR agonist, but not the LHRH antagonist degarelix, induces atherosclerotic plaque instability in ApoE-/- mice. In: EAU 2015, Poster 559. Madrid.

27. Knutsson A, Hsiung S, Celik S, Rattik S, Mattisson IY, et al. (2016) Treatment with a GnRH receptor agonist, but not the $\mathrm{GnRH}$ receptor antagonist degarelix, induces atherosclerotic plaque instability in ApoE(-/-) mice. Scientific reports 6: 26220.

28. Fachinformation (2014) FIRMAGON $80 \mathrm{mg}$ Pulver und Lösungsmittel zur Herstellung einer Injektionslösung. Ferring GmbH. 011697-7981 - Stand der Information Oktober.

29. Keating NL, O'Malley A, Freedland SJ, Smith MR: Diabetes and cardiovascular disease during androgen deprivation therapy: observational study of veterans with prostate cancer. Journal of the National Cancer Institute 104: 1518-1523.

30. Van Hemelrijck M, Garmo H, Holmberg L, Ingelsson E, Bratt O, et al. (2010) Absolute and relative risk of cardiovascular disease in men with prostate cancer: results from the Population-Based PCBaSe Sweden. Journal of clinical oncology: Official journal of the American Society of Clinical Oncology 28: 3448-3456.

31. Jespersen CG, Norgaard M, Borre M (2014) Androgen-deprivation therapy in treatment of prostate cancer and risk of myocardial infarction and stroke: a nationwide Danish population-based cohort study. European urology 65: 704-709.

32. Tsai HK, D'Amico AV, Sadetsky N, Chen MH, Carroll PR (2007) Androgen deprivation therapy for localized prostate cancer and the risk of cardiovascular mortality. Journal of the National Cancer Institute 99: 1516-1524.

33. Saigal CS, Gore JL, Krupski TL, Hanley J, Schonlau M, et al. (2007) Androgen deprivation therapy increases cardiovascular morbidity in men with prostate cancer. Cancer 110: 1493-1500.

34. Hu JC, Williams SB, O'Malley AJ, Smith MR, Nguyen PL, et al. (2012) Androgendeprivation therapy for nonmetastatic prostate cancer is associated with an increased risk of peripheral arterial disease and venous thromboembolism. European urology 61: 1119-1128.

35. Gandaglia G, Sun M, Popa I, Schiffmann J, Abdollah F, et al (2014) The impact of androgen-deprivation therapy (ADT) on the risk of cardiovascular (CV) events in patients with non-metastatic prostate cancer: a population-based study. BJU international 114: E82-89.

36. Alibhai SM, Duong-Hua M, Sutradhar R, Fleshner NE, Warde P, et al. (2009) Impact of androgen deprivation therapy on cardiovascular disease and diabetes. Journal of clinical oncology: official journal of the American Society of Clinical Oncology 27: 3452-3458.

37. Schmid M, Sammon JD, Reznor G, Kapoor V, Speed JM, et al. (2015) Dosedependent effect of androgen deprivation therapy for localized prostate cancer on adverse cardiac events. BJU international
38. Efstathiou JA, Bae K, Shipley WU, Hanks GE, Pilepich MV, et al. (2009) Cardiovascular mortality after androgen deprivation therapy for locally advanced prostate cancer: RTOG 85-31. Journal of clinical oncology : official journal of the American Society of Clinical Oncology 27: 92-99.

39. Bolla M, Van Tienhoven G, Warde P, Dubois JB, Mirimanoff RO, et al. (2010) External irradiation with or without long-term androgen suppression for prostate cancer with high metastatic risk: 10-year results of an EORTC randomised study. The Lancet Oncology 11: 1066-1073.

40. Wilcox C, Kautto A, Steigler A, Denham JW (2012) Androgen deprivation therapy for prostate cancer does not increase cardiovascular mortality in the long term. Oncology 82: 56-58.

41. Nguyen PL, Je Y, Schutz FA, Hoffman KE, Hu JC, et al. (2010) Association of androgen deprivation therapy with cardiovascular death in patients with prostate cancer: a meta-analysis of randomized trials. JAMA : The journal of the American Medical Association 306: 2359-2366.

42. Smith MR, Klotz L, van der Meulen E, Colli E, Tanko LB (2011) Association of baseline risk factors with cardiovascular (CV) events during long-term degarelix therapy in men with prostate cancer. Journal of clinical oncology : Official journal of the American Society of Clinical Oncology 2011.

43. Albertsen PC, Klotz L, Tombal B, Grady J, Olesen TK, Nilsson J (2014) Cardiovascular morbidity associated with gonadotropin releasing hormone agonists and an antagonist. European urology 65: 565-573.

44. Tombal B, Miller K, De Reijke TM, Persson BE (2013) Degarelix versus luteinising hormone-releasing hormone (LHRH) agonists: Safety outcomes from six comparative randomised clinical trials. European Journal of Cancer 2: 681.

45. Radu A, Pichon C, Camparo P, Antoine M, Allory Y, et al. (2010) Expression of follicle-stimulating hormone receptor in tumor blood vessels. The New England journal of medicine 363: 1621-1630.

46. Hanke H, Lenz C, Hess B, Spindler KD, Weidemann W (2010) Effect of testosterone on plaque development and androgen receptor expression in the arterial vessel wall. Circulation 103: 1382-1385.

47. Ng MK, Quinn CM, McCrohon JA, Nakhla S, Jessup W, et al. (2003) Androgens up-regulate atherosclerosis-related genes in macrophages from males but not females: molecular insights into gender differences in atherosclerosis. Journal of the American College of Cardiology 42: 1306-1313.

48. Klotz L, Miller K, Crawford ED, Shore N, Tombal B, et al. (2014) Disease control outcomes from analysis of pooled individual patient data from five comparative randomised clinical trials of degarelix versus luteinising hormone-releasing hormone agonists. European urology 66: 1101-1108.

Citation:

Behrouz Kherad, Spillmann F, Noutsias M, Tschöpe C and Krackhardt F (2017) Androgen Deprivation Therapy and Cardiovascular Risk. Cancer Stud Ther J Volume 2(7): 1-6 